\title{
血管内焼灼術後に残存ないし再発した下肢静脈瘤に対する エコーガイド下硬化療法のすすめ
}

\author{
田代 秀夫
}

\begin{abstract}
○要 約：血管内焼灼術後にも再発ないし残存した静脈瘤の逆流起始部にエコーガイド下フォーム硬化療 法（UGFS:Ultrasound-guided Foam Sclerotherapy）を試みたので報告する。2018年1月～2019年4月にUGFS を行った 51 例 55 肢を対象とした。部位別には，下腿不全交通枝 20 肢，大伏在静脈 12 肢，小伏在静脈 8 肢, 伏在静脈分枝再発2肢, 副伏在静脈と Giaconomi Veinの各1肢であった. 1 3\%の Polidocanol Foamを逆流 の起始部静脈内に $1 \mathrm{~mL}$ 以下で使用し，圧迫枕子と弾性包帯で固定した，翌朝以後，弾性ストッキング着用を 励行した。術後1 カ月前後の超音波検査にて 55 肢中 52 肢において逆流消失を認め，3肢は，弾性ストッキン グが着用できず，術後の圧迫不良のため，再度の硬化療法を要した。平均観察期間（10.2力月）中，早期の 再燃ならびに合併症は経験していない。焼灼術後に残存ないし再発した静脈瘤へのエコーガイド硬化療法は, 低侵襲かつ安全な治療手段である。
\end{abstract}

索引用語: 下肢静脈瘤, 血管内焼灼術, エコーガイド下フォーム硬化療法, 再発性下肢静脈瘤, 穿通枝不全

静脈学 $2020 ; 31(1): 21-24$

はじめに

伏在静脈の弁不全による逆流を主因とする下肢静脈 瘤の治療は，分枝を処理する高位結䅨と Stripping手 術であったことも今は昔である。今般の血管内焼灼術 は, 焼灼中枢側の血栓形成：EHIT（Endo-venous Heatinduced Thrombosis）の懸念から焼灼部位を大腿伏在接 合部：SFJ（Sapheno-femoral Junction）より約 $2 \mathrm{~cm}$ 末梢 側から行う，いわば低位結紮術ともいうべき妥協的治療 であり, SFJ近傍からの分枝再発 ${ }^{1)}$ は, 避けられない. また，焼灼術後にかかわらず，副伏在静脈や不全交通枝 に逆流のある場合には, 静脈瘤の再燃も早く, 燒灼術以 外の治療戦略が無いと患者さんは, 放置されることにな る.内視鏡下不全穿通枝結禁術 : SEPS (Subfascial Endoscopic Perforator Surgery $)^{2)}$ により逆流ポイントを結

ユーカリ血管クリニック

受付：2019年10月8日受理：2019年12月20日

doi: 10.7134/phlebol.19-21

\section{(cc) BY-NC-ND}

禁，さらに外科的に静脈瘤切除となれば侵襲は少なくな い. 昨今, 不全交通枝に対する低侵襲治療としてエコー ガイド下の硬化療法 : UGFS (Ultrasound-guided Foam Sclerotherapy）が国外では第一選択となり，良好な成 績 ${ }^{3)}$ が報告されており，本邦でも普及が望まれる現況 にある。当院でも残存ないし再発静脈瘤にPolidocanol Foamを用いてUGFSを試みたので，その手技および初 期成績につき報告する。

\section{対象と方法}

2018年1月～2019年 4 月に硬化療法を施行した下肢 静脈瘤366例のうち, UGFS を行った51例 55 肢を対象 とした。部位別には，下腿不全交通枝27肢，大伏在静 脈 15 肢, 小伏在静脈 9 肢, 大伏在静脈分枝再発 2 肢, 副 伏在静脈と Giaconomi Veinの各1肢であった。逆流部 位は, 分枝再発を除くと深部静脈からの交通枝ないし 新生血管を介して伏在静脈に逆流を生じていた。 UGFS は, $1 \mathrm{ccシリンジに} 30 \mathrm{G}$ 針（針長 $18 \mathrm{~mm}$ ) を装着, 1〜 $3 \%$ の Polidocanol Foam（Tessari法により air $0.5 \mathrm{~mL}$ と polidocanol $0.5 \mathrm{~mL}$ で調製）を逆流の起始部静脈を超音 
(A)

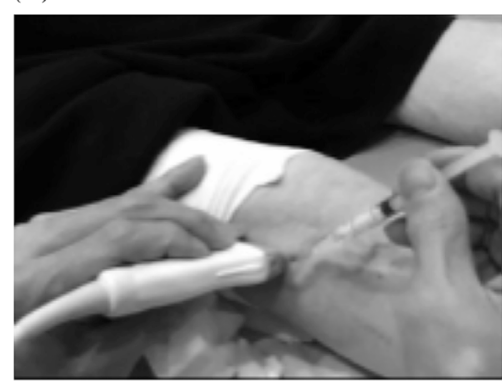

(B)

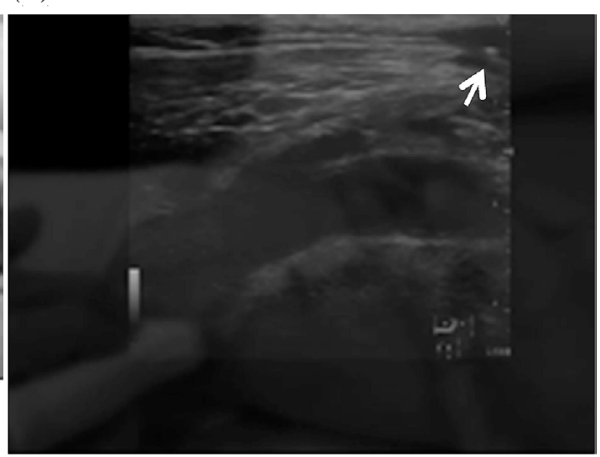

Fig. 1 Ultrasound- guided sclerotherapy for the recurrent varicose veins.

(A) Ultrasound probe was attached on the skin surface to visualize subcutaneous varices. (B) The needle $(\uparrow)$ was inserted into the varicose vein under ultrasound guidance.

(A)

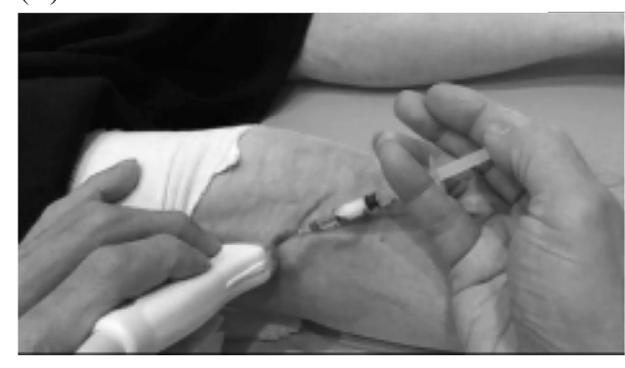

(B)

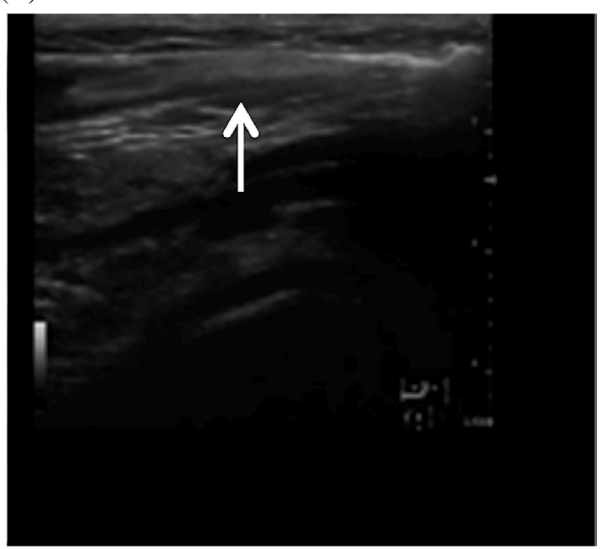

Fig. 2 (A) Foam sclerosant was injected into varicose vein, following the reflux of venous blood was confirmed. (B) The sclerosant was spread into the small saphenous vein $(\uparrow)$ via varicose vein.

波プローブで描出しつつ，その断層面に沿って穿刺針を 静脈内に刺入，血液の逆流を認めた時点で注入した。静 脈内にハレーションが広がり, 深部静脈に及ばないこ とを確認してから，30秒程度，薬液を停滞させたのち， 圧迫枕子を当てて弾性包带により圧迫固定した，翌朝 以後，弾性ストッキング着用を夜間を除き，1力月間励 行した。薬液使用量は, 1 力所 $1 \mathrm{~mL}$ 以下とした。なお, air と薬液は $1: 1 て ゙$, half foamで調製した。使用薬剤の 濃度は，打掞むね，静脈径を基準に $3 \mathrm{~mm}$ 未満； $1 \% ， 4$ 〜 $5 \mathrm{~mm}$; 2\%，5 mmを超える； $3 \%$ を使用した。

\section{治療手技および成績}

Fig. 1Aは, 小伏在静脈高位結柇後の再発症例で, 結 紮部位より中枢側から静脈箇へ逆流を生じていたので, 小伏在静脈を長軸方向にエコープローブを走査しつつ描 出した，静脈径と逆流の程度を勘案してPolidocanolを $2 \%$ Foam（1\%，3\%液を同量混和）に $30 \mathrm{G}$ 針を装着した $1 \mathrm{cc}$ シリンジに充填, 皮膚面を酒精綿で拭き取ったのち
穿刺，針の先端が静脈内にあることを超音波画像上で確 認（Fig. 1B），シリンジ内への逆流を視認してから硬化 剤の注入を緩徐に行った（Fig. 2A）。静脈瘤内の Foam 薬剤のハレーションが, 深部静脈に及ばないよう超音 波画面上で観察しつつ注入を終了，ひきつづき静脈内の Foam硬化剤の停滞を確認したのち（Fig. 2B）, 圧迫枕 子を置いて弾性包带で固定した。翌朝, 包带, 圧迫枕子 をはずし，弾性ストッキングの着用を夜間を除き励行， 術後28～35 日の期間に超音波ドップラー検查：D-US （Dopplar Ultra-Sonography）を全例に施行したところ, 55 肢中 52 肢に打いて, 治療部位は閉塞し, 逆流は消失 した，3肢は，硬化療法後の圧迫不良（弾性ストキング 未装着）のため, 再度, 硬化療法を行い根治した。平均 観察期間は 10.2 力月であるが，早期の再燃ならびに合 併症は経験していない.

\section{考察}

下肢静脈瘤におけるThe UK National Institute for 
Health and Care Excellenceが2013年に発表したガイド

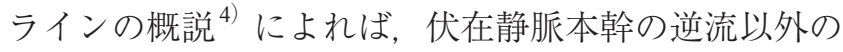
non-saphenous reflux（不全交通枝を含む）による静脈瘤 治療や伏在静脈本幹逆流治療後の残存静脈瘤や, 外科 手術および血管内焼灼術後に再発した静脈瘤に対する UGFSは，第一選択の治療法として推奨され，海外では 広く実施されている。手技的には，簡便であり，比較的 太い静脈瘤でも逆流の程度に応じて 1 3\%の Foam硬化 剤をピンポイントで注入することで, 術後の弾性ストッ キング着用が継続できた症例は, 全例において逆流起始 部の静脈が閉塞した，昨今の血管内焼灼術の急速な普及 に比へ，焼灼術後の残存ないし再発静脈瘤に対して手つ かずの症例を散見する現状を憂い，小生もかつて本会 誌に投稿 ${ }^{5)}$ したが, 依然, 硬化療法は限られた専門家 ${ }^{6)}$ のみの手に委ねられたままである。硬化剤のpolidocanol は，2006年に本邦において上市され，当初，血管内 焼灼術による治療症例の急増に伴い, 硬化療法も著しく 需要が増すことが予想されたが, 新規参入の医師には, 硬化療法の技術伝承が充分に及ばなかったように思う。 小生とてその責を免れるものではないが, せめてもの償 いに本稿を残し，適正な下肢静脈瘤硬化療法を見直す機 会になれば幸いである。

\section{結 語}

血管内焼灼術あるいは外科手術後にも残存ないし再 発した静脈瘤に対するエコーガイド硬化療法（UGFS）
は，低侵襲かつ安全な治療手段であり，ピンポイント治 療が可能であった。

\section{利益相反}

本論文について利益相反はない.

$$
\text { 付 記 }
$$

本論文の要旨は第39回日本静脈学会総会（2019年, 名古屋)で発表した，座長推薦論文.

エコーガイド硬化療法は，10数年前より報告された 保険適用のある治療手技であり，倫理的承認を要する治 療ではない。また，症例に関しても治療部位の撮影を患 者より承諾を得て行われた。

\section{文献}

1) 鈴木 修: 下肢静脈瘤治療に抢ける非造影3DCT静脈造影の有用 性. 静脈学 2016; 27: 267-273

2) 草川 均, 小津泰久, 井上健太郎, 他：下腿部の穿通枝もしくは 伏在静脈本幹に逆流源を有する再発性下肢静脈瘤に対する手術症 例の検討. 静脈学 2016; 27:259-265

3) Kuyumcu G, Salazar GM, Prabhakar A, et al: Minimally invasive treatment for perforator vein insufficiency. Cardiovasc Diagn Ther 2016; 6: 593-598

4) Kemp N: A synopsis of current international guidelines and new modalities for the treatment of varicose veins. AFP 2017; 46: 229-233

5) 田代秀夫：下肢静脈瘤治療における可視化硬化療法の歩み。静脈 学 2014; 25: 415-420

6) 八巻 隆, 野崎幹弘, 櫻井博之, 他: 下肢静脈瘤一液状硬化療法 からフォーム硬化療法へ. 脈管学 2009; 49: 225-231 


\title{
Abstract \\ Recommendation of Ultrasound-guided Foam Sclerotherapy for Residual or Recurrent Varicose Veins after Endovascular Thermal Ablation or Surgery
}

\author{
Hideo Tashiro
}

Yukari Vascular Clinic

Key words: varicose vein, endo-venous thermal ablation, ultrasound-guided foam sclerotherapy, varicose vein recurrence, perforator vein insufficiency

Currently, minimally invasive treatment including ultrasound-guided foam sclerotherapy (UGFS) is widely applied. However, in our country, the report concerning about UGFS is extremely rare. Between January 2018 and April 2019, we have performed UGFS for the residual or recurrent varices of 55 limbs in 51 patients after endovascular thermal ablation or surgery. The injection sites of sclerosant, using $1-3 \%$ polidocanol foam $(<1 \mathrm{~mL})$ are as follows; Incompetent perforator below the knee 10 cases, saphenous vein (Great 12, Short 8), saphenous tributary vein 2, accessory saphenous vein 1 and Giaconomi vein 1 case, respectively. After sclerotherapy, the compression was continued using bandage with pads overnight, then elastic stockings at least one month. The Doppler ultrasound examination has revealed that the venous reflux was disappeared 52 of 55 limbs 4 weeks later (28-35 day) post-sclerotherapy. The reflux remaining three cases was due to incomplete compression without elastic stocking, but residual reflux was disappeared by the additional sclerotherapy. The UGFS is effective and safe strategy for residual or recurrent varices, because no complication has occurred during follow up period ;mean 10.2 month post-sclerotherapy.

Jpn J Phlebol 2020; 31(1): 21-24 